\title{
Emisja metanu z zespołów zaporowo-upustowych
}

\begin{abstract}
W artykule przedstawiono metodologie pomiarów wielkości emisji metanu z zespołów zaporowo-upustowych oraz wyniki pomiarów emisji tego gazu z tego typu obiektów. Zostały one wykorzystane do określenia współczynników emisji metanu dla zespołów zaporowo-upustowych, a następnie do przeprowadzenia inwentaryzacji emisji metanu z dwóch wybranych odcinków gazociągów.
\end{abstract}

Słowa kluczowe: zespoły zaporowo-upustowe, emisja metanu, gazociągi.

\section{Methane emission from shut off and relief valve systems}

The article presents the methodology of measurement of methane emissions from shut off and relief valve systems and the results of measurements of methane emissions from such facilities. The measurements were used to determine the methane emission factors from shut off and relief valve systems and then to make an inventory of methane emissions from two selected sections of gas pipelines.

Key words: shut off and relief valve systems, methane emission, gas pipelines.

\section{Wstęp}

Wydobycie gazu ziemnego oraz systemy przesyłu, dystrybucji i magazynowania tego paliwa są źródłem emisji metanu do atmosfery. Szacuje się, że około $37 \%$ całkowitej wielkości emisji metanu na świecie związanej z wydobyciem, przeróbką i transportem gazu ziemnego pochodzi z sektora przesyłu i magazynowania tego gazu [4]. Wszystkie elementy systemu przesyłowego, takie jak tłocznie gazu, stacje gazowe, zespoły zaporowo-upustowe oraz gazociągi, są źródłem emisji metanu. Emisja ta wiąże się z:

- wyciekami gazu z poszczególnych elementów systemu (emisja lotna związana z nieszczelnościami),

- pracami eksploatacyjnymi (np. emisje związane z upustami),

- awariami.

Niniejszy artykuł poświęcony został wyłącznie oszacowaniu wielkości emisji lotnej metanu z zespołów zaporowoupustowych (ZZU) występujących w systemie przesyłowym GAZ-SYSTEM S.A. oraz ocenie jej wpływu na wielkość całkowitej emisji lotnej tego gazu z gazociągów przesyłowych.
Emisja związana z wyciekami gazu z poszczególnych elementów systemu, nazywana emisją lotną, w odróżnieniu od pozostałych rodzajów emisji jest zjawiskiem nieuniknionym - usuwane są wykryte nieszczelności, a w ich miejsce pojawiają się nowe. Jednak dzięki stosowaniu coraz lepszych materiałów i technologii emisje lotne maleją. Emisja lotna metanu $\mathrm{z}$ dowolnego elementu systemu gazowego wyliczana jest na podstawie równania (1) $[2,3,6-8,13]$ :

$$
\text { Emisja }=\Sigma(A F \cdot E F)
$$

gdzie:

$A F$ - współczynnik aktywności (activity factor), określający wielkość populacji danego źródła emisji (np. liczba ZZU),

$E F$ - współczynnik emisji (emission factor), zdefiniowany jako ilość metanu emitowana $\mathrm{z}$ danego typu źródła emisji, które może ją powodować.

Ze względu na dużą liczbę i różnorodność znajdujących się w systemie przesyłowym elementów emitujących metan 
często zdarza się, że współczynnik emisji nie jest wyliczany, a jedynie szacowany na podstawie dostępnych danych statystycznych, w związku z czym może być obarczony dużą niepewnością. Drugim istotnym parametrem niezbędnym do określenia wielkości emisji są współczynniki aktywności poszczególnych jej źródeł $(A F)$, które wyrażają wielkość populacji danego źródła (w przypadku zespołów zaporowo-upustowych jest to ich liczba).

W zależności od szczegółowości posiadanych danych dotyczących systemu szacowanie wielkości emisji metanu może być realizowane na trzy sposoby (podejścia) [2, 3, 6-8, 13]. W PODEJŚCIU 1, najmniej szczegółowym, wielkość emisji metanu jest wyliczana ogólnie dla całego sektora, w zależności od ilości transportowanego gazu. Zaletę tego podejścia stanowi niewielka liczba informacji niezbędnych do określenia wielkości emisji, wadę natomiast - duża niepewność dokonanych oszacowań oraz brak możliwości wyznaczenia wielkości emisji metanu $z$ danego, interesującego nas elementu systemu, np. z ZZU. Z tego też względu w niniejszym artykule rozwiązanie to nie zostało uwzględnione. PODEJŚCIE 2 jest bardziej szczegółowe od PODEJŚCIA 1, a co za tym idzie - wyniki wykonanych oszacowań są znacznie dokładniejsze. Jego zastosowanie wymaga jednak posiadania ogólnych informacji o inwentaryzowanym systemie, takich jak długość sieci oraz liczba poszczególnych jej elementów, tj. tłoczni, stacji redukcyjno-pomiarowych czy zespołów zaporowo-upustowych. PODEJŚCIE 2 wymaga również określenia współczynników emisji $(E F)$ osobno dla każdego z elementów. Ostatnie, najbardziej szczegółowe PODEJŚCIE 3 obarczone jest najmniejszą niepewnością. Ten sposób inwentaryzacji wielkości emisji metanu można zastosować, jeżeli podczas inwentaryzacji dysponuje się szczegółowymi danymi charakteryzującymi poszczególne elementy systemu. W przypadku zespołów zaporowo-upustowych są to informacje dotyczące m.in. wieku, ciśnienia czy typu ZZU. PODEJŚCIA 2 i 3 pozwalają nie tylko na szacowanie wielkości emisji metanu z całego systemu, ale również na ocenę wkładu poszczególnych elementów w całkowitą wielkość emisji lub przeprowadzenie inwentaryzacji wyłącznie dla jednego wybranego elementu systemu.

Podczas dokonywania wyboru sposobu prowadzenia inwentaryzacji wielkości emisji metanu (według PODEJŚCIA 1, 2 lub 3) należy pamiętać, że wraz ze wzrostem szczegółowości danych rośnie stopień skomplikowania wykonywanych obliczeń, ale też w znaczący sposób maleje niepewność oszacowania wielkości emisji.

W dalszej części artykułu przedstawiono i porównano wyniki oszacowania wielkości emisji metanu z ZZU wykonane według PODEJŚCIA 2 i PODEJŚCIA 3.

\section{Metodyka badań}

W celu określenia wielkości emisji metanu z ZZU przeprowadzono kontrolę szczelności oraz pomiar wielkości emisji metanu na 60 wybranych do badań obiektach. Badania prowadzono na bardzo zróżnicowanych obiektach. Były wśród nich zespoły zaporowo-upustowe podziemne (40 szt.) oraz nadziemne (20 szt.), zespoły typu kątowego (24 szt.), przelotowego (30 szt.) oraz włączeniowego (6 szt.). Wybrane obiekty były zróżnicowane pod względem wieku, ciśnienia i wielkości. W badaniach uwzględniono ZZU od zupełnie nowych, jednorocznych lub dwuletnich ( 8 szt.), po zespoły ponad czterdziestoletnie ( 8 szt.); średnia wieku badanych ZZU wynosiła około 14 lat. Również wartości ciśnień maksymalnych i roboczych na rozpatrywanych obiektach zmieniały się w szerokich zakresach, odpowiednio od 2,5 MPa do 8,4 MPa oraz od 1,5 MPa do 5,8 MPa, co przekładało się na stopień wykorzystania ciśnienia MOP, mieszczący się w przedziale $60 \div 80 \%$. Badane zespoły posiadały od 1 do 4 zaworów głównych. $\mathrm{O}$ ich zróżnicowanej wielkości może świadczyć również fakt, że liczba elementów odcinających (kurków i zasuw) zainstalowanych na danym ZZU wynosiła od 1 do 26. Wybrane do badań ZZU były także bardzo zróżnicowane pod względem sposobu łączenia elementów odcinających z elementami armatury. W $30 \mathrm{z}$ badanych ZZU zasto- sowano głównie połączenia kołnierzowe, na 12 ZZU dominowały połączenia spawane, na 4 - gwintowane, natomiast w przypadku pozostałych 13 zespołów zaporowo-upustowych nie można było wskazać dominującego rodzaju połączeń ze względu na to, że co najmniej dwa ich typy występowały równie często na danym obiekcie.

Podczas pomiarów wielkości emisji metanu z ZZU wykorzystano dwie metody pomiarowe emisji metanu z opływem powietrza wokół badanego elementu.

Pierwsza podstawowa metoda badawcza (METODA 1) wykorzystywała do pomiaru wielkości emisji urządzenie Hi Flow Sampler, które pozwala na pomiar w zakresie od 0,1 1/min do $225 \mathrm{l} / \mathrm{min}$. Druga z metod badawczych (METODA 2) to autorskie rozwiązanie opracowane w INiG - PIB, wykorzystujące do pomiarów wielkości emisji metanu następujące urządzenia:

- aparat do pomiaru niskich stężeń węglowodorów PortaFid M3K firmy Herman Sewerin GmbH, o zakresie pomiarowym od 1 ppm do 10000 ppm lub

- aparat GA 2000 firmy Geotech o zakresie pomiarowym dla metanu od $1 \%$ do $100 \%$,

- gazomierze miechowe o zakresie pomiarowym $0,04 \div 10 \mathrm{~m}^{3} / \mathrm{h}$ oraz

- stoper. 
Opracowana przez INiG - PIB metoda pozwala na pomiar emisji metanu w zakresie od 0,0008 1/min do $380 \mathrm{l} / \mathrm{min}$. Podczas badań metodę tę stosowano jedynie w zakresie, w którym nie było możliwości wykorzystania METODY 1 , tj. od $0,0008 \mathrm{l} / \mathrm{min}$ do $0,1 \mathrm{l} / \mathrm{min}$. W tym przedziale METODA 2 charakteryzuje się $50 \%$ niepewnością.

\section{Wyznaczenie współczynników emisji metanu dla zespołów zaporowo-upustowych}

Wyniki prowadzonych badań wykazały, że $28 \%$ badanych obiektów jest nieemisyjnych, natomiast stwierdzone na pozostałych obiektach wielkości emisji metanu mieszczą się w zakresie od $0,001 \mathrm{~m}^{3} /$ doba do $14,976 \mathrm{~m}^{3} /$ doba. Uśrednienie wielkości emisji zmierzonej na wszystkich badanych 60 ZZU pozwoliło na określenie współczynnika emisji metanu z ZZU według PODEJŚCIA 2. Wyznaczony zgodnie z tym podejściem współczynnik wyniósł $1,507 \mathrm{~m}^{3} / \mathrm{szt}$./doba. Określenie współczynników emisji metanu dla PODEJŚCIA 3 wymagało dodatkowo przeanalizowania, które parametry charakteryzujące ZZU są istotne z punktu widzenia wielkości emisji tego gazu. Pod uwagę wzięto takie parametry jak:

- typ ZZU,

- posadowienie,

- wiek,

- ciśnienie, w tym maksymalne MOP, robocze oraz stopień wykorzystania ciśnienia MOP,

- wielkość ZZU, w tym liczbę zaworów głównych oraz liczbę elementów odcinających,

- dominujący rodzaj połączeń stosowanych na ZZU, w tym spawane, kołnierzowe, gwintowane oraz ZZU bez dominującego rodzaju połączenia.

W celu dokonania oceny, czy dany parametr charakteryzujący ZZU ma istotny wpływ na wielkość emisji metanu, badane obiekty podzielono na grupy względem każdego z wymienionych powyżej parametrów. Następnie analizowano, jak zmieniała się średnia wielkość emisji metanu w grupach wraz ze zmianą wybranego parametru. Tam, gdzie było to pomocne, przeprowadzono test statystyczny służący do weryfikacji hipotezy zerowej $\left(H_{0}\right)$, mówiącej o równości wariancji pomiędzy populacjami wyników. Dla wykonywanych testów przyjęto poziom istotności równy $\alpha=0,05$. Przeprowadzona ocena pozwoliła stwierdzić, że trzy z wymienionych parametrów charakteryzujących ZZU mają wypływ na wielkość emisji metanu. W przypadku pozostałych parametrów cechujących badane obiekty wykonane obliczenia wykazały brak ich wpływu na wielkość emisji metanu lub wpływ ten pokrywał się z innymi czynnikami, np. wiekiem ZZU. Parametrami charakteryzującymi ZZU istotnymi z punktu widzenia emisji metanu są:

- typ ZZU z podziałem na trzy grupy (kątowe, przelotowe i włączeniowe),

- wiek ZZU z podziałem na trzy grupy (wiek ZZU $<11$ lat, $11 \leq$ wiek ZZU $\leq 20$ lat i wiek ZZU > 20 lat) oraz

- stopień wykorzystania ciśnienia MOP z podziałem na dwie grupy (poniżej 70\% oraz powyżej 70\% ciśnienia MOP). Przeprowadzona analiza pozwoliła na pogrupowanie ZZU na 15 kategorii i przypisanie każdej z nich osobnego współczynnika emisji zgodnie z PODEJŚCIEM 3. Wyznaczone w PODEJŚCIU 3 współczynniki emisji metanu z ZZU zmieniały się w szerokim zakresie od $0 \mathrm{~m}^{3} / \mathrm{szt}$./doba do $8,111 \mathrm{~m}^{3} / \mathrm{szt}$./doba. Należy dodać, że współczynniki te w przypadku sześciu kategorii nie przekraczały $0,1 \mathrm{~m}^{3} / \mathrm{szt}$./doba.

\section{Inwentaryzacja emisji metanu dla przykładowego odcinka gazociągu}

Uzyskane przy zastosowaniu PODEJŚCIA 2 i 3 współczynniki emisji posłużyły do przeprowadzenia inwentaryzacji emisji metanu z dwóch przykładowych odcinków gazociągów. Pierwszy analizowany odcinek gazociągu, o długości $60 \mathrm{~km}$, został wybudowany w latach 2007-2011 i wyposażony w 11 ZZU (ODC 1). Drugi, o długości 119 km, wybudowano w latach 1970-2011 i wyposażono w 34 ZZU (ODC 2). W celu oszacowania wielkości emisji metanu z obu wymienionych odcinków gazociągów wykorzystano wyznaczone na podstawie badań współczynniki emisji metanu z ZZU oraz wybrany na podstawie danych literaturowych i przeliczony na odpowiednią zawartość metanu współczynnik emisji metanu dla gazociągów przesyłowych (równy $0,018 \mathrm{~m}^{3} / \mathrm{km} /$ doba) $[1,4,5]$. Współczynnik ten został przyjęty ze względu na to, że jest rekomendowany dla gazociągów przesyłowych wykonanych ze stali i objętych ochroną, a większość gazociągów należących do GAZ-SYSTEM S.A. to gazociągi tego typu. Oszacowaną - na podstawie współczynników emisji metanu wyznaczonych dla ZZU i przyjętego na podstawie literatury dla gazociągów - wielkość emisji metanu z wybranych odcinków gazociągów przedstawiono w tablicy 1.

Analiza danych przedstawionych w tablicy 1 pozwala stwierdzić, że emisje lotne metanu z ZZU są istotnym elementem wpływającym na całkowitą wielkość emisji tego gazu z gazociągów. Wpływ ten może się jednak zmieniać w szerokim zakresie w zależności od charakterystyki ZZU zlokalizowanych na danym odcinku gazociągu. W przypadku młodszego z gazociągów, którego wiek nie przekroczył 10 lat (ODC 1), dużo niższe wyniki inwentaryzacji emisji metanu uzyskać można, stosując PODEJŚCIE 3. Spowodowane 
Tablica 1. Szacunkowa wielkość emisji metanu z dwóch odcinków gazociągów

\begin{tabular}{|c|c|c|c|c|}
\hline & \multirow{2}{*}{\multicolumn{4}{|c|}{ Wielkość emisji metanu [m³/rok] }} \\
\hline & & & & \\
\hline & \multicolumn{2}{|c|}{ ODC 1} & \multicolumn{2}{|c|}{ ODC 2} \\
\hline & PODEJŚCIE 2 & PODEJŚCIE 3 & PODEJŚCIE 2 & PODEJŚCIE 3 \\
\hline ZZU & 6050 & 2238 & 18701 & 36909 \\
\hline Część liniowa gazociągu & \multicolumn{2}{|c|}{394} & \multicolumn{2}{|c|}{781} \\
\hline Suma & 6444 & 2632 & 19483 & 37691 \\
\hline
\end{tabular}

jest to tym, że wszystkie ZZU zlokalizowane w obrębie tego odcinka należą do dwóch niskoemisyjnych kategorii ZZU, dla których współczynniki emisji mieszczą się w przedziale od $0 \mathrm{~m}^{3} / \mathrm{szt}$./doba do $0,876 \mathrm{~m}^{3} / \mathrm{szt}$./doba, a więc są niższe niż średni współczynnik emisji metanu wyznaczony w PODEJŚCIU 2. Odwrotnie przedstawia się sytuacja w przypadku drugiego gazociągu (ODC 2), dla którego wielkość emisji metanu oszacowana z zastosowaniem PODEJŚCIA 3 jest znacznie wyższa niż przy wykorzystaniu PODEJŚCIA 2. Związane jest to z wiekiem gazociągu, który powoduje, że większość zlokalizowanych na nim ZZU należy do kategorii wysokoemisyjnych. Wśród 34 ZZU zlokalizowanych na tym odcinku gazociągu, aż 25 charakteryzuje się współczynnikiem emisji wyższym niż 1,507 m3/szt./doba.

\section{Wnioski}

Przeprowadzone badania wykazały, że wśród badanych ZZU wyróżnić można zarówno obiekty nieemisyjne, jak i takie, dla których zmierzona wielkość emisji metanu wynosiła ponad $14 \mathrm{~m}^{3} /$ doba. Świadczy to o dużym zróżnicowaniu ZZU pod względem wielkości emisji metanu. Średnia wielkość tej emisji z ZZU dla badanych obiektów, będąca jednocześnie współczynnikiem emisji metanu dla ZZU według PODEJŚCIA 2, wynosi $1,507 \mathrm{~m}^{3} /$ szt./doba. Podczas określania współczynników emisji metanu dla ZZU według PODEJŚCIA 3 należy uwzględnić takie parametry charakteryzujące ZZU jak typ, wiek oraz stopień wykorzystania ciśnienia MOP. Wzięcie pod uwagę tych cech ZZU pozwoliło na podział badanych obiektów na 15 kategorii oraz przypisanie im współczynników emisji według PODEJŚCIA 3. Wyznaczone dla tego podejścia współczynniki emisji metanu zmieniają się w szerokim zakresie: od $0 \mathrm{~m}^{3} / \mathrm{szt}$./doba do $8,111 \mathrm{~m}^{3} / \mathrm{szt}$./doba. Zastosowanie wyznaczonych współczynników emisji na dwóch wybranych odcinkach gazociągów pozwoliło stwierdzić, że w przypadku nowych gazociągów niższe wyniki inwentaryzacji emisji metanu uzyskuje się z zastosowaniem PODEJŚCIA 3, natomiast w przypadku gazociągów starszych niż 20 letnie z zastosowaniem PODEJŚCIA 2.
Należy jednak pamiętać, że prowadzenie inwentaryzacji według PODEJŚCIA 3, z uwzględnieniem typu ZZU oraz jego charakterystyki wiekowej i ciśnieniowej, powinno prowadzić do otrzymania dokładniejszych wyników.

Dotychczasowe badania pozwoliły wskazać kierunek dalszych prac badawczych w zakresie inwentaryzacji emisji metanu z ZZU i gazociągów. Kolejne badania prowadzone przez GAZ-SYSTEM S.A. we współpracy z INiG - PIB będą obejmowały grupę ZZU charakteryzujących się różnorodnością połączeń oraz odcinki gazociągów występujących na terenach górniczych, których dodatkowym elementem są kompensatory.

Efektem końcowym prowadzonych badań będzie określenie współczynnika emisji dla części liniowej systemu przesyłowego, uwzględniającego zarówno ZZU, gazociągi, jak i kompensatory.

Aktualizacja sposobu raportowania emisji z systemu przesyłowego wpłynie pozytywnie na wiarygodność wyników oszacowania emisji, a tym samym na podejmowanie miarodajnych działań mających na celu zmniejszenie negatywnego wpływu systemu przesyłowego na środowisko naturalne.

Prosimy cytować jako: Nafta-Gaz 2016, nr 7, s. 534-538, DOI: 10.18668/NG.2016.07.06

Artykuł nadesłano do Redakcji 1.02.2016 r. Zatwierdzono do druku 21.04.2016 r.

Artykuł powstał na podstawie referatu zaprezentowanego na Konferencji Naukowo-Technicznej FORGAZ 2016 „Techniki i technologie dla gazownictwa - pomiary, badania, eksploatacja”, zorganizowanej przez INiG - PIB w dniach 13-15 stycznia 2016 r. w Muszynie. 


\section{Literatura}

[1] American Petroleum Institute: Compendium of greenhouse gas emission methodologies for the oil and natural gas industry. 2009, s. 6-24.

[2] Eggleston H. S., Buendia L., Miwa K., Ngara T., Tanabe K. (eds.): 2006 IPCC Guidelines for National Greenhouse Gas Inventories. IPCC, Japan, IGES, 2006, s. 119

[3] Eurogas - Marcogaz: Guidelines for choosing methane emission factor. 2006, s. 4

[4] Harrison M. R., Campbell L. M. Shires T. M., Cowgill R. M.: Methane emission from the natural gas industry, Vol. 2: Technical Report. EPA-600/R-96-080b, U.S. Environmental Protection Agency, Office of Research and Development, Washington 1996, s. 14, 25.

[5] Intersate Natural Gas Association of America (INGAA): Greenhouse gas emission estimation guidelines for natural gas transmission and storage, Vol. 1 - GHG emission estimation methodologies and procedures. 2005, s. 59-61.

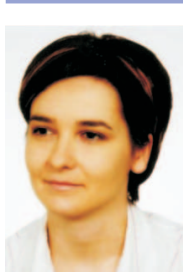

Dr Ewa KUKULSKA-ZAJĄC

Adiunkt; kierownik Zakładu Ochrony Środowiska. Instytut Nafty i Gazu - Państwowy Instytut Badawczy ul. Lubicz 25 A

31-503 Kraków

E-mail: kukulska@inig.pl
[6] Lott R. A.: Methane Emissions from U.S. Natural Gas Operations. IGU/D4-94, s. 11-12.

[7] Riva A.: Development of a Eurogas - Marcogaz methodology for estimation of methane emissions. European Forum Gas, Paris 12-13.09.2007, s. 4.

[8] Steczko K., Rachwalski J.: Emisja metanu z sieci rozdzielczej gazu ziemnego. Nafta-Gaz 2007, nr 11, s. 412-423.

\section{Mgr Jadwiga HOLEWA-RATAJ}

Starszy specjalista badawczo-techniczny w Zakładzie Ochrony Środowiska.

Instytut Nafty i Gazu - Państwowy Instytut Badawczy

ul. Lubicz 25 A

31-503 Kraków

E-mail: jadwiga.holewa@inig.pl

\section{OFERTA}

\section{ZAKŁAD OCHRONY ŚRODOWISKA}

Zakres działania:

- $\quad$ analiza zagrożeń środowiska, związanych z działalnością przemysłu naftowego i gazowniczego,

- opracowanie i weryfikacja technologii środowiskowych w przemyśle nafty i gazu,

- $\quad$ monitoring i badania laboratoryjne jakości środowiska (powietrza, wód i gleby) na terenach poszukiwania i eksploatacji złóż węglowodorów i innych terenach przemysłowych,

- $\quad$ badania laboratoryjne ścieków (w tym wód złożowych i cieczy technologicznych) i odpadów (w tym odpadów wiertniczych, odpadów po zabiegu hydraulicznego szczelinowania) oraz ocena ich potencjalnej szkodliwości dla środowiska,

- Klasyfikacja odpadów wydobywczych wraz ze sporządzaniem podstawowej charakterystyki odpadu,

- $\quad$ analiza zawartości rtęci w próbkach środowiskowych (stałych i ciekłych), mieszaninach gazowych i materiałach przemysłowych,

- $\quad$ inwentaryzacja emisji metanu z sektora poszukiwania, wydobycia, magazynowania oraz przesyłu i dystrybucji gazu,

- ocena wielkości emisji gazów cieplarnianych,

- ocena jakości paliw węglowodorowych: gazu ziemnego, koksowniczego, gazów wytwarzanych w przemyśle, biogazu,

- $\quad$ kompleksowa analiza biogazu, w tym analiza związków krzemu, chloru i fluoru,

- $\quad$ monitoring jakości gazu ziemnego w systemie gazowniczym,

- badania podkładów kolejowych odpadowych, wykorzystywane do ich klasyfikacji pod względem bezpieczeństwa dla środowiska,

- $\quad$ sporządzanie oraz aktualizacja kart charakterystyki substancji i mieszanin niebezpiecznych, zgodnie z obowiązującym prawodawstwem,

- $\quad$ pobór próbek wód, ścieków, gleb, odpadów oraz gazu ziemnego, biogazu i innego typu mieszanin gazowych.

Kierownik: dr Ewa Kukulska-Zając

Adres: ul. Bagrowa 1, 30-733 Kraków

Telefon: 12617743

Faks: 126531665

E-mail: ewa.kukulska@inig.pl 